\title{
Prevalence and Determinants of Anemia during Pregnancy at Hodeida City, (Yemen) during the Year 2021
}

\author{
Nabil M. H. Gonaid ${ }^{1}$, Salwa El-Sanousi ${ }^{2}$, Hussien Kadi ${ }^{3}$ \\ ${ }^{1}$ Lecturer of Community Medicine, Faculty of Medicine, Hodeida University, Yemen \\ ${ }^{2}$ Professor of Community Medicine, Faculty of Medicine, Gezira University, Sudan \\ ${ }^{3}$ Professor of Pharmacology and Therapeutics, Faculty of Pharmacy, Sana'a University, Yemen \\ Corresponding Author: Nabil M. H. Gonaid
}

DOI: https://doi.org/10.52403/ijhsr.20220304

\begin{abstract}
Background: Anemia in pregnancy (AIP) is a global public health problem reaching prevalence as $41.8 \%$ globally, and up to $54 \%$ in Middle East region. It accounts for $20 \%$ of global maternal deaths. In Yemen, prevalence of AIP is $40 \%$. It consists part of high complicated maternal mortality ratio which reached 164 according last Yemeni demographic health survey reports. The study aimed to assess AIP prevalence and determinants at Hodeida city, Yemen.

Methods: Cross sectional study conducted on 500 pregnant women who were selected from Hodeida health centers, their data collected through structured pretested questionnaire, $\mathrm{Hb}$ of study members had been assessed through hemoglobinometer.

Data Analysis: Data statistically analyzed through SPSS program (version 22) using descriptive statistics, Chi square test for investigating the association between AIP and the independent factors.

Results: The study revealed AIP prevalence as 55\%. It revealed statistically significant determinants of AIP including husband education $(\mathrm{P}=0.000)$, mother education $(\mathrm{P}=0.10)$, mother concerned health knowledge $(\mathrm{P}=0.000)$, suffering from over menses $(\mathrm{P}=0.000)$, family socioeconomic level $(\mathrm{P}=0.000)$, food sufficiency $(\mathrm{P}=0.02)$, food diversity $(\mathrm{P}=0.087)$, supplementary feeding support $(\mathrm{P}=0.05)$, Khat chewing habit $(\mathrm{P}=0.094)$ and post meal tea drinking $(\mathrm{P}=0.043)$, while no significant association found for mother age $(\mathrm{P}=0.144)$, parity $(\mathrm{P}=0.690)$, pregnancy trimester $(\mathrm{P}=0.414)$, breastfeeding $(\mathrm{P}=0.581)$ and using contraceptives $(\mathrm{P}=0.208)$.
\end{abstract}

Conclusion: Anemia in pregnancy at Hodeida city is a sever public health problem according WHO classification. Socio economic and nutritional factors are representing its roots.

Key words: Anemia, Pregnancy, Prevalence, Determinants.

\section{INTRODUCTION}

Yemen is one of the least developed countries in the world, and one of the poorest countries in the middle east with reported food scarcity, high illiteracy especially in females ${ }^{(1)}$. Differing from Yemeni official figure of 164 as maternal mortality ratio, UNFPA reported it during 2019 as $385^{(2)}$.

Yemen is among countries which had negatively affected by Arab spring events of 2011, and had fallen into protracted conflict ${ }^{(3)}$. The war and siege on Yemen had a devastating impact on the health of women and children ${ }^{(4)}$. Evidence demonstrated that the health effects of conflict on women and children were neglected ${ }^{(5)}$.

Hodeida is a coastal governorate at the west of Yemen. It is one of the highest population governorates in Yemen, It has around 3 million peoples mostly working in 
a primitive agriculture and fishing. It has highest poverty and the lowest human development indices. It comprises 26 districts; It has been classified by ministry of public health and population (MOPHP) among the most governorates suffering from malnutrition ${ }^{(6)}$.

The global prevalence of AIP is estimated as $41.8 \%$, and in more than $80 \%$ of countries in the world, the prevalence of AIP had estimated at 29\%. It reaches around $50 \%$ in low- and middle-income countries including Middle East region (7). AIP is associated with increased maternal, neonatal and perinatal mortality, low birth weight, premature birth, and delayed child development. Also AIP has a significant effect on nutritional status of young children leading to stunting and underweight. AIP globally accounts for $12 \%$ of Low birth weight, $19 \%$ of pre-term birth, and $18 \%$ of perinatal mortality ${ }^{(8)}$. According to study in 29 countries across Latin America, Africa, the Western Pacific, eastern Mediterranean, and Southeast Asia, maternal death in women with severe anemia found to be higher compared with those without severe anemia ${ }^{(9)}$. Further studies reached a strong association between moderate to severe anemia at 28 weeks of gestation and the severity of intra and postpartum hemorrhage (10). Iron deficiency anemia (IDA), is the main cause of AIP, while intestinal worms infestations; (particularly, hookworm and malaria) worsen the problem of anemia in many areas worldwide (11). In Yemen prevalence of AIP is $40 \%$. It consisting a significant part of high complicated maternal mortality ratio. Scope of this study is to explore prevalence and determinants of AIP in Hodeida city, Yemen.

\section{METHODS}

A cross-sectional study conducted on pregnant women attending anti natal care clinics at 17 health centers in Hodeida city during the period (mid-November 2020-mid January 2021).

\section{Sampling}

Sample size had been calculated using on line computerized soft program ${ }^{(12)}$ estimating number of pregnant women is 27104 (according population projections for the year 2020) and assuming the prevalence of AIP in Hodeida city is going with Yemeni national figure as $40 \%{ }^{(13)}$. The total calculated representative sample with $5 \%$ error yielded was 379 . The sample size was increased to 500 to improve the precision of the study. Sample size had been divided over the three districts of Hodeida city (AlHali, Al-Hawak, Al-Miena) according population density, by the ratio $(40 \%, 35 \%$, $25 \%$ ) respectively. Health centers (HCs) from each of the three districts had been selected according to the client attendance rate, thus all high and average attendance rated HCs in the three districts were selected and they reached $17 \mathrm{HCs}$. The quota of each district of study sample had divided on its selected HCs according health center attendance rate by the ratio ( $3: 2$ for high attendance against average attendance $\mathrm{HC}$ ).

The study sample per district and health center has revealed in (table1)

Table 1: Study sample distribution per HC, district.

\begin{tabular}{|c|c|c|c|}
\hline \multirow[t]{2}{*}{ District name } & \multirow[t]{2}{*}{ Name of health center } & \multicolumn{2}{|c|}{ cases } \\
\hline & & No. & $\%$ \\
\hline \multirow[t]{8}{*}{ Al-Hali district } & Al-Hali HC & 26 & $5.2 \%$ \\
\hline & Al-Senaeei HC & 34 & $6.8 \%$ \\
\hline & Palestine HC & 32 & $6.4 \%$ \\
\hline & Al-Zaafran HC & 30 & $6 \%$ \\
\hline & Al Salakhanah MCH center & 44 & $8.8 \%$ \\
\hline & Al-Kedf HC & 20 & $4 \%$ \\
\hline & Al-Baida Al-gharbiah HC & 17 & $3.4 \%$ \\
\hline & Al Hali total study cases & \multicolumn{2}{|l|}{203} \\
\hline \multirow{6}{*}{$\begin{array}{l}\text { Al-Hawak } \\
\text { district }\end{array}$} & Al-Hawk HC & 31 & $6.2 \%$ \\
\hline & Al-Shahariah HC & 33 & $6.6 \%$ \\
\hline & Al- Rabassah HC & 33 & $6.6 \%$ \\
\hline & Al-Thawrah MCH center & 45 & $9 \%$ \\
\hline & Al-Qasr HC & 20 & $4 \%$ \\
\hline & $\begin{array}{l}\text { Al Hawak total study } \\
\text { cases }\end{array}$ & \multicolumn{2}{|l|}{162} \\
\hline \multirow[t]{7}{*}{ Al-Miena district } & Al-Zabariah HC & 35 & $7 \%$ \\
\hline & Al-Bostan HC & 26 & $5.2 \%$ \\
\hline & Al-Tahrir HC & 37 & $7.4 \%$ \\
\hline & Al-Ommal HC & 25 & $5 \%$ \\
\hline & Al-Qalaa HC & 12 & $2.4 \%$ \\
\hline & Al Miena total study cases & \multicolumn{2}{|l|}{135} \\
\hline & Grand total study cases & 500 & $100 \%$ \\
\hline
\end{tabular}

\section{Data collection}

Data collected by well-trained health staff according a previously prepared and pre tested data collection tool through 
Nabil M. H. Gonaid et.al. Prevalence and determinants of anemia during pregnancy at Hodeida city, (Yemen) during the year 2021.

interviewing the consenting pregnant women in antenatal care clinics of the selected health centers.

Table 2: Scheme for scoring breast feeding commitment

\begin{tabular}{|l|l|}
\hline Item & Score \\
A-Exclusive breast feeding period & \\
-Less than 6 months & 2 \\
-6 months & 4 \\
B-Whole period of breast feeding & 1 \\
-Up to 6 months & 2 \\
-6-12 months & 3 \\
-More than 12 months & \\
Total scoring & $0-4$ \\
-Weak & $5-6$ \\
-Average & 7 \\
-Good &
\end{tabular}

Information in the questionnaire included socio demographic characteristics such as age, occupation and educational status, nutritional patterns and habits, mother concerned health knowledge and behavior. $\mathrm{Hb}$ had been tested after completing the interview by hemoglobinometer.
Socioeconomic standards of study members had been scored using modified scoring system after Fahmi and Sherbini (14) while innovative schemes for scoring other addressed independent factors in this study had been used as revealed in tables (2$6)$.

Table 3: Scheme for scoring food sufficiency

\begin{tabular}{|l|l|}
\hline Item & Score \\
A-Number of daily meals & 1 \\
-1-2 meals per day & 2 \\
-3 meals per day & 3 \\
-More than 3 meals & \\
B -Post meal satisfying & 1 \\
-Rarely & 2 \\
-Some times & 3 \\
-Usually & \\
C-Peoples sharing meals & 4 \\
-Her kids & 3 \\
-Her husband and kids & 2 \\
-Two families members & 1 \\
-More than 2 families members & \\
Total scoring & $0-4$ \\
- Poor & $5-7$ \\
-Average & $8-10$ \\
- Good & \\
\hline
\end{tabular}

Table 4: Scheme for scoring food diversity

\begin{tabular}{|l|l|l|l|}
\hline Items & Marks & Items & Marks \\
\hline A-Meats in meals & & C-Fruits and vegetables in meals & \\
Many times & 4 & Many times & 3 \\
Some times & 3 & Some times & 2 \\
Rarely & 2 & Rarely & 1 \\
Very rarely & 1 & & \\
\hline B - Cereals and Beans in meals & & Total scoring & \\
Many times & 3 & Good & $8-10$ \\
Some times & 2 & Average & $5-7$ \\
Rarely & 1 & Poor & $0-4$ \\
\hline
\end{tabular}

Table 5: Scheme for scoring khat chewing intensity.

\begin{tabular}{|l|l|l|l|l|l|}
\hline Days of chewing per week & Marks & Hours of chewing per day & Marks & Total marks & scoring interpretation \\
\hline 1-2 days & 1 & $1-3$ hours & 1 & 2 & Mild \\
Most days & 2 & $3-5$ hours & 2 & $3-4$ & Moderate \\
Every day & 3 & More than five hours & 3 & $5-6$ & Intense \\
\hline
\end{tabular}

Table 6: Scheme for scoring mother concerned health knowledge's

\begin{tabular}{|l|l|l|l|}
\hline Mothers' knowledges & $\begin{array}{l}\text { Anemia symptoms } \\
\text { Marks }\end{array}$ & $\begin{array}{l}\text { Locally available foods rich of iron and vitamin c } \\
\text { (marks) }\end{array}$ & Total marks scoring \\
\cline { 2 - 5 } Total marks & Score \\
\hline Doesn't know & 0 & 0 & $0-1$ \\
\hline Knows 1-2 items & 1 & 1 & Bad \\
\hline $\begin{array}{l}\text { Knows more than 2 } \\
\text { items }\end{array}$ & 2 & 2 & 4 \\
\hline
\end{tabular}

\section{Data Entry and Analysis:}

SPSS (version 22) had been used for data entry and analysis.

Cronbach Alpha test had been conducted and concluded (as shown in table 7), that a questionnaire has a high level of internal consistency and reliability.

Table 7. Cronbach Alpha test out puts

\begin{tabular}{|l|l|l|l|}
\hline $\mathbf{N}$ & Items & Cronbach Alpha & Stability \\
\hline $\mathbf{5 0 0}$ & $\mathbf{6 4}$ & $\mathbf{0 . 7 1}$ & $\mathbf{0 . 8 4}$ \\
\hline \multicolumn{4}{|c|}{ Source: SPSS 2021 output based on survey data }
\end{tabular}

Descriptive statistics (frequencies, percentages, means and standard deviation) had been used, and Chi square test had been used for investigating the association between initial anemic state and the independent variables of study, given by formula: $\chi^{2}=\sum(\mathrm{Oi}-\mathrm{Ei}) 2 / \mathrm{Ei}$ Where: $\mathrm{Oi}=$ observed value (actual value) and $\mathrm{Ei}=$ expected 


\section{RESULT}

A)-The study revealed Prevalence of AIP among study sample as $55 \%(\mathrm{~N}=275)$.

B)- Determinants of anemia in pregnancy has shown in (table 8):

Table8. Statistical significance of independent factors

\begin{tabular}{|c|c|c|c|}
\hline Independent factors & $\begin{array}{l}\text { Chi } \\
\text { square }\end{array}$ & df & P value \\
\hline Husband education & $15.389 \mathrm{a}$ & 3 & $0.000 * * *$ \\
\hline Family socio economic level & $24.279 \mathrm{a}$ & 2 & $0.000 * * *$ \\
\hline AIP concerned health knowledge & $28.168 \mathrm{a}$ & 2 & $0.000^{* * * *}$ \\
\hline History of over menses & $32.164 a$ & 1 & $0.000 * * *$ \\
\hline $\begin{array}{l}\text { History of Malaria and Intestinal } \\
\text { helminthes }\end{array}$ & $29.616 a$ & 6 & $0.000^{* * *}$ \\
\hline Post meal tea drinking & $3.457 \mathrm{a}$ & 1 & $0.043 * *$ \\
\hline Food sufficiency & $14.972 \mathrm{a}$ & 6 & $0.02 * *$ \\
\hline SFP support & $2.744 \mathrm{a}$ & 1 & $0.05 * *$ \\
\hline Mother education & $5.930 \mathrm{a}$ & 3 & $0.10 *$ \\
\hline Khat chewing & $6.401 \mathrm{a}$ & 3 & $0.094 *$ \\
\hline Food diversity & $4.878 \mathrm{a}$ & 2 & $0.087 *$ \\
\hline Mother age group & $.668 \mathrm{a}$ & 1 & 0.144 \\
\hline Parity & $.743 a$ & 2 & 0.690 \\
\hline Pregnancy trimester & $.668 \mathrm{a}$ & 1 & 0.414 \\
\hline History of contraception & $3.137 \mathrm{a}$ & 2 & 0.208 \\
\hline Breastfeeding & $1.958 \mathrm{a}$ & 3 & 0.581 \\
\hline \multicolumn{4}{|c|}{$\begin{array}{l}\text { Source: Researcher own survey data, } 2021 \\
* * * \text { Significant at } 1 \% \text { level of significance } \\
* * \quad \text { Significant at } 5 \% \text { level of significance } \\
* \quad \text { Significant at } 10 \% \text { level of significance }\end{array}$} \\
\hline
\end{tabular}

As revealed in table 8 the study had found: I- Statistically high significant association of AIP $(\mathrm{P}$ value $=0.00)$ with husband education, mother AIP concerned health knowledge, family socio economic level, history of over menses, History of parasitic infections and Malaria.

II-Statistically mid significant association of AIP with post meal tea drinking ( $P$ value $=0.04)$, Low food sufficiency $(\mathrm{P}$ value $=0.02)$, Getting SFP support $(\mathrm{P}$ value $=0.05$ )

III- Statically slight significant association of AIP with mother education level $(P$ value $=0.1)$, Low food diversity $(\mathrm{P}$ value $=0.09)$, Khat chewing habit $(\mathrm{P}$ value $=0.087$ )

IV- Statically non-significant association of AIP with Age of pregnant woman ( $P$ value $=0.414)$, Parity $(P$ value $=0.690)$, pregnancy trimester $(\mathrm{P}$ value $=0.427)$, history of using contraceptive $(\mathrm{P}$ value $=0$. 208), Breastfeeding $(\mathrm{P}$ value $=0.581)$.

\section{DISCUSSION}

Prevalence of AIP concluded by present study is $55 \%(\mathrm{~N}=275)$, is higher than Yemeni national figure by $15 \%{ }^{(13)}$, and equaling the prevalence of AIP in Dhamar governorate according recent Yemeni study (15). The higher AIP prevalence revealed in the present study compared to national figure could be explained by the 11 years deference between the Yemeni DHS (which had conducted during 2010) and the present study (which had been conducted during 2021 and the economic drawback effects occurred during this period in Yemen.

Regarding determinants of AIP according 15 studies conducted in developing countries from 2000 to 2015, factors such as increased maternal age, low education, high parity, poor socio-economic status, and poor nutritional status have been found as important determinants ${ }^{(16)}$. Also multi-parity had been also concluded in some studies as AIP determinant ${ }^{(17)}$. In the present study, high statistically significant decrease of AIP had found associating increased husband education; this could be attributed to the dominant role of the husband in decision taking in Yemeni family. Husband education also found to be significantly associating mother adherence to iron and folic acid (IFAS) treatment at Denbiya district health centers, Northwest Ethiopia ${ }^{(18)}$. In the present study, also high statically significant decreased tendency of AIP found associating increased level of mother concerned health knowledge, same outputs had been reached by many studies such as study conducted in southern region of KSA ${ }^{(19)}$. Also low maternal concerned health knowledge had been linked with higher prevalence of AIP in study conducted in Harar town, Ethiopia ${ }^{(20)}$.

Present study revealed high statistically significant association of AIP with low family socio economic level, This is going With outputs of a study of determinants of anemia in women of reproductive age which had been conducted in Sudan ${ }^{(21)}$, a study of determinants of AIP 
in Nigeria ${ }^{(22)}$ and AIP study conducted in a tertiary care centers in Karachi; Pakistan ${ }^{(23)}$.

Iron loss consequent to excessive menstrual discharge is by far the most frequent cause of iron-deficient anemia ${ }^{(24)}$. The present study revealed high statistically significant association of AIP with history of over menses. This is supported by outputs of a study conducted on Caucasian women aged 20-45 years ${ }^{(25)}$, and according Saudi study, there was significant increase of AIP prevalence among mothers who suffered from menorrhagia ${ }^{(26)}$.

Malaria is one of the primary causes of anemia globally and intestinal helminthes are among common causes of anemia ${ }^{(27)}$, in the present study high statistically significant association of AIP found with history of malaria and intestinal helminthes. There are many supporting studies of these outputs including Sudanese study (28), and Ethiopian study ${ }^{(29)}$.

The present study also had found mid significant association of AIP with post meal tea drinking, most probably due to the inhibitory effect of tannin on iron absorption. Tea drinking had been proved in many studies as a significant determinant of anemia, such as Yemeni study conducted among Hodeida university students ${ }^{\left({ }^{(0)} \text {, and }\right.}$ Saudi study conducted among female university students in Tabuk, Saudi Arabia (31).

The present study showed mid significant decreased tendency of AIP associating increased food sufficiency, this is supported by evidence from nationally representative surveys of seven south and southeast Asian countries ${ }^{(32)}$, and AIP study conducted in South Africa ${ }^{(33)}$.

The present study showed mid significant increased tendency of AIP among mothers getting supplementary feeding programs (SFP) support, which could be understood as they were selected to benefit from SFP programs because they were malnourished, so they were suffering also from anemia, this is supported by results of mentioned above south and south eastern Asian survey ${ }^{(32)}$, and Algerian study which reached significant association of AIP with malnutrition in the 3rd trimester of pregnancy ${ }^{(34)}$.

The present study showed slight significant decreased tendency of AIP associating increased mother education level, these significance also revealed in outputs of many studies including a study conducted at Soba University Hospital, Khartoum State Sudan ${ }^{(28)}$, study conducted in Dhaka city Bangladesh (35) and in findings from Ethiopian health and demographic survey ${ }^{(36)}$. Also the present study shown slight significant decreased tendency of AIP associating increased food diversity score, this output is supported by study on University Students in Hodeida Province, Yemen ${ }^{(30)}$ and a study in rural Ethiopia ${ }^{(37)}$.

Khat is derived from the fresh leaves and buds of Catha edulis which is very popular in some African countries and Yemen. Recently Khat chewing became common among pregnant women in Yemen (38). The present study showed slight significant association between Khat chewing and AIP. This is supported by above mentioned Yemeni study conducted among Hodeida university students ${ }^{(30)}$.

No significant association reached in the present study between AIP and the age of pregnant woman, as not reached too in Sudanese study conducted during $2018{ }^{(39)}$, and study conducted in Libya ${ }^{(40)}$. All could make impression of the weakness of the role of the age as a determinant of AIP.

Also parity did not proved according the present study as significant determinant as meeting with outputs of studies conducted in Libya (40) and United Arab Emirates ${ }^{(41)}$, all denoting the role of parity as a determinant of AIP might be hidden by other determinants.

Although, many studies revealed significant association of AIP with the advance in pregnancy trimester such a study conducted in Qatar ${ }^{(42)}$, and Jordan ${ }^{(43)}$, the present study and previous study conducted in in Ghana ${ }^{(44)}$ did not reach this significant link. Controversies in out puts of studies 
her, could be explained as the physiological effect of advance in pregnancy on $\mathrm{Hb}$ which had proved as risk factor in some areas of the world might be compensated by other factors at other areas. Also the significant effect of using contraceptives on decreasing anemia prevalence which reached by Saudi study conducted in Alniaryah province ${ }^{(45)}$, a studies conducted in northern Nigeria (46) and Sri Lanka ${ }^{(47)}$, did not reached in the present study might be due to supposed non enough periods of using contraceptives among users in the present study to protect them against anemia through avoiding monthly blood loss. Also, the present study did not reach significant link for breast feeding with AIP such reported in Iraqi study ${ }^{(48)}$.

\section{CONCLUSION}

The aim of this study was to assess the prevalence and determinants of AIP in Hodeida city, The study revealed AIP prevalence in Hodeida city as $55 \%$, and the study revealed that, (couple education, mother concerned health knowledge, suffering from over menses, family socioeconomic level, food sufficiency and diversity, supplementary feeding programs support, Khat chewing habit and post meal tea drinking), all found as statistically significant determinants of AIP, while no significant association found with (mother age and parity, pregnancy trimester, breastfeeding and using contraceptives).

\section{Acknowledgment}

High gratitude for directors at Hodeida health office, concerned districts health offices, and health centers for their support and cooperation. Special thanks to midwife at health centers in Hodeida city for their nice work during field work.

\section{Ethical Approval}

The proposal for this research was approved by community and family medicine department in Faculty of medicine at Gezira University, Sudan, as a part of proposal for PHD degree. Research had approved by research ethics committee at Yemen University, Yemen.

\section{Conflict of Interest}

The authors report no conflict of interest regarding this report.

\section{Source of Funding: None}

\section{REFERENCES}

1. UNCDP. List of Least Developed Countries (as of December 2018). United Nations committee for development policy; 2018.

2. UNFPA.Reproductive health equity in the Arab region: Fairness and Social Success, Regional report; 2019.

3. UNDP. Arab Human Development Report; 2016.

4. El Bcheraoui Charbel, Jumaan Aisha O, Collison Michael L, Daoud Farah and Mokdad Ali H. Health in Yemen: losing ground in war time. Bio Med Central. 2018; 14 (42): p 1.

5. Kedir H, BerhaneY, and Worku A. Khat chewing and restrictive dietary behaviors are associated with anemia among pregnant women in high prevalence rural communities in Eastern Ethiopia. PLoS ONE. 2019; 8(11): 78601.

6. Yemen NIC. National information center: Governorates section. (Accessed on 2020/1/20)

website:http://www.yemennic.info/yemen/ gover_old/

7. Yang Fan, Xuey iLiu, Panpan Zha. Trends in socioeconomic inequalities and prevalence of anemia among children and non-pregnant women in Low-and MiddleIncome Countries. JAMA Network Open. 2018; 1(5):e182899. Downloaded From: https://jamanetwork.com/ on 10/12/2020

8. UNICEF. Technical bulletin No 25, Copenhagen: UNICEF; 2018.

9. Jahnavi Daru, Javier Zamora, Borja M Fernández Félix, Joshua Vogel, Olufemi T Oladapo et al. Risk of maternal mortality in women with severe anaemia during pregnancy and postpartum: a multilevel analysis. Lancet Glob Health. 2018; 6:548-54, available on March 20, 2018 at 
web site http://dx.doi.org/10.1016/S2214109X(18) 30078-0

10. Gian Carlo Di Renzo. Good clinical practice advice: Iron deficiency anemia in pregnancy. Int J Gynecol Obstet. 2019; 144: 322-324

11. Titaley CR, Dibley MJ, Roberts CL, Agho K. Combined iron/folic acid supplements and malaria prophylaxis reduce neonatal mortality in 19 sub-Saharan African countries. Am J Clinical Nutrition. 2010;92(1):235-43

12. On line calculator. Sample Size Calculator. (Accessed on 2015/1/20) at website:

http://www.calculator.net/sample-sizecalculator

13. YNCB. Yemen DHS 2013: initial report; Yemeni national center for Biostatistics; 2013.

14. Fahmy SI, El-Sherbini AF. Determining simple parameters for social classification for health research. Bull HIPH. 1983; 13:95-107.

15. Mogahed Fuad Y, Al-Qudari Ahmed Y, Akydy Ahmed G. Iron deficiency anemia and associated risk factors among pregnant women in Dhamar city, Yemen. Al-Saeeda Journal of Medical Sciences. 2019;1 (1):1 - 11

16. Ali Sumera Aziz, Khan Umber and Feroz Anam. Prevalence and determinants of anemia among women of reproductive age in developing countries. J Coll Physicians Surg Pak. 2020;30(2):177-186

17. Iftikhar Aisha, Bari Attia, Zeeshan Fatima, Jabeen Uzma, Masood Qaisar et al. Maternal anemia and its impact on nutritional status of children under the age of two Years. Biomed J Sci \& Tech Res. 2018; 5(3) 4519-22.

18. Tarekegn Missa, Wubshet Mamo, Atenafu Azeb and others. Antenatal care and mothers education improved iron-folic acid adherence at Denbiya district health centers, Northwest Ethiopia: using pills count method. Archives of Public Health. 2019; 77:30.

19. Dhaher Enas A. Descriptive study for pregnant women's knowledge, attitude and practices regarding iron deficiency anemia and iron supplements in the
Southern Region of KSA. Asian Journal of Clinical Nutrition. 2020; 12 (1):21-33.

20. Oumer Abdo, Hissien Aref. Pregnant mothers knowledge, attitude and practice towards preventions of iron deficiency anemia in Harar town Ethiopia. International Journal of public health sciences. 2019;8(2):202-210

21. Elmardi Khalid Abdelmutalab, Adam Ishag, Malik Elfatih Mohammed and others. Prevalence and determinants of anemia in women of reproductive age in Sudan: analysis of a cross-sectional household survey. BMC Public Health. 2020; 20:1125.

22. Ugwu $\mathrm{N}$ and Uneke CJ. Iron deficiency anemia in pregnancy in Nigeria; A Systematic Review. Niger J Clin Pract. 2020; 23:889-96.

23. Zehra Tabassum, Khan Rafeeq Alam and Qadir Farida. Anemia in pregnancy: a study of Karachi in a tertiary care centre. American Journal of Phytomedicine and Clinical Therapeutics. 2014; 2(10) 12241233.

24. WHO. Guideline: Intermittent iron and folic acid supplementation in menstruating women. Geneva, World Health Organization; 2011.

25. Napolitano Mariasanta, Dolce Alberto, Celenza Giuseppe and others. Iron dependent erythropoiesis in women with excessive menstrual blood losses and women with normal menses. Annals of Hematology. 2014; 557-563.

26. Taha Asia, Azhar Saira, Lone Talib and others. Iron deficiency anemia in reproductive age women attending obstetrics and gynecology outpatient of university health center in Al-Asha, Saudia Arabia. Afr J Tradit Complement Altern Med. 2014;11(2):339-342

27. White NJ. Anaemia and malaria. Malaria Journal. 2018;17: 371

28. Babeker Nadia Elfadil Mohamed, Hassan Rania Hassan Abd-algafor. Prevalence and factors associated with anemia among pregnant women attending ante-natal clinic in the second and third trimesters at Soba University Hospital, Khartoum State, Sudan 2018-2019. International 
Journal of Health Sciences and Research. 2020;10(8); 195-204.

29. Amelo Bolka and Samson Gebremedhin. Prevalence of intestinal parasitic infection and its association with anemia among pregnant women in Wondo Genet district, Southern Ethiopia: a cross-sectional study. BMC Infectious Diseases. 2019; 19:483.

30. Al-alimi Abdullah Ahmed, Bashanfer Salem, and Morish Mohammed Abdo. Prevalence of iron deficiency anemia among University Students in Hodeida province, Yemen. Hindawi Anemia. 2018; Article ID 4157876, https://doi.org/10.1155/2018/4157876

31. Riyadh A Alzaheb1 and Osama Al-Amer. The prevalence of iron deficiency anemia and its associated risk factors among a sample of female university students in Tabuk, Saudi Arabia. Women's Health Journal. 2017; 10:1-8

32. Sunuwar Ram, Devendra Raj Singh, Narendra Kumar Chaudhary and others. Prevalence and factors associated with anemia among women of reproductive age in seven South and Southeast Asian countries: Evidence from nationally representative surveys. PLoS ONE. 2020; $15: 8$

33. Vinogrin Dorsamy, Chauntelle Bagwandeen and Jagadesa Moodley et al. The prevalence, risk factors and outcomes of anaemia in South African pregnant women: a protocol for a systematic review and meta- analysis. BMC, Systematic Reviews. 2020; 9(209): 1

34. Tebbani Fouzia, Oulamara Hayet and Agli Abdenacer. Gestational Anemia: The factors associated and the outcomes in the mother and the infant. Clinics Mother Child Health; 2020

35. Chowdhury Hasina Akhter, Ahmed Kazi Rumana, Jebunessa Fatema and others. Factors associated with maternal anemia among pregnant women in Dhaka city. BMC Women's Health. 2015; 15:77.

36. Ataklti Gebretsadik Woldegebriel, Gebremedhin Gebregziabiher Gebrehiwot , Abraham Aregay Desta and others. Determinants of anemia in pregnancy:findings from the Ethiopian health and demographic survey. Hindawi
Anemia. 2020; (Accessed on 2020/9/15) at website

37. Taddese A Zerfu, Melaku Umeta, and Kaleab Baye. Dietary diversity during pregnancy is associated with reduced risk of maternal anemia, preterm delivery, and low birth weight in a prospective cohort study in rural Ethiopia. American Journal of Clinical Nutrtion. 2016; 103:1482-8.

38. Al-abed Ali, Sutan Roznah, Al-Dubaei Sami, Aljunid Sayed. Family context and Khat chewing among adult Yemeni women: a cross-sectional study. Biomed Research International. 2014; (accessed on 2021/12/8) at web site https://doi.org/10.1155/2014/505474

39. Adam Ishaq, Ibrahim Yassin and Alhardello Osama. Prevalence, types and determinants of anemia in pregnant women in Sudan: a systemic review and meta-analysis. BMC Hematology. 2018; 18:31

40. Elzahaf Raga A. and Omar Mariam. Prevalence of anaemia among pregnant women in Derna city, Libya. Int $\mathbf{J}$ Community Med Public Health. 2016; 3(7): P1915-1920.

41. Shahwan Moyad J, Hassan Nageeb A. and Sada Nada M. Prevalence of anemia and its associated factors among pregnant women attending anti natal center in Sharjah, UA. International Journal of Pharmaceutical Sciences and Research. 2019; 10(11):5002-5009.

42. Selim Nagah Abdel Aziz, Al-Mass Mariam, Al-Kuwari Mohammed and others. Assessment of Anemia, IDA and ID among Pregnants in Qatar: Cross Sectional Survey. SM Journal of Public Health and Epidemiology.2016; 2(3): 2(3): 1035

43. Salahat Mohammad A. and Ibrahim Abdullah I. Prevalence of Anemia among Jordanian Pregnant Women and the Effect of Early Pregnancy on Alkaline Phosphatase Activity. Jordan Journal of Biological Sciences. 2012;5:(1): 65 - 70

44. Kofie Philip, Tarkang Elvis E., Manu Emmanuel and others. Prevalence and associated risk factors of anaemia among women attending antenatal and post-natal 
clinics at a public health facility in Ghana. BMC Nutrition. 2019;5(40):1-6

45. Abuelgasim Mohammed, ElSayed Ahmed Esmat and Hafez Ahmed Sherif. Prevalence and epidemiological aspect of Anemia Among Pregnant Women Attending Antenatal Care Centers in Alniaryah province Eastern Saudi Arabia. Thesis submitted for partial fulfillment of Master degree in Family medicine; 2014.

46. Nwizu EN, Iliyasu Z, Ibrahim SA and Galadanci HS. Socio-Demographic and Maternal Factors in Anaemia in Pregnancy at Booking in Kano, Northern Nigeria. African Journal of. Reproductive Health.2011; 15(4)1

47. Pitigala Kalharie. Cultural factors associated with iron deficiency anemia in pregnancy: A case study of the Kalutara district Sri Lanka. 2nd Global Public Health Conference. 2019; 2: 62-65.

48. Hussien Alaa, Sha'lan and Ali Saadalddin Hussien. The Prevalence of Anemia among Internally Displaced Families residing in well-defined camps in Baghdad City. Nutrition Research Institute Baghdad ; 2016.

How to cite this article: Nabil M. H. Gonaid, Salwa El-Sanousi, Hussien Kadi. Prevalence and determinants of anemia during pregnancy at Hodeida city, (Yemen) during the year 2021. Int J Health Sci Res. 2022; 12(3):23-31. DOI: https://doi.org/10.52403/ijhsr.20220304 